\title{
CEPHALIC TETANUS: Case Report of a Rare Complication of Orbito-ocular Injury in a Nigerian
}

\author{
"OA OGUN, M.B.; B.S. (Ib.) \\ AO ASHAYE, M.B.; B.S. (Ib.) FWACS, FMPCOphth \\ Department of Ophthalmology. College of Medicine, University of Ibadar, Ibadan Nigeria \\ SO OLA, M.B.;B.S. II .) FWACP \\ Department of Medicine, College of Medicine, University of madan, Ibadan Nigeria
}

\section{SUMMARY}

\section{Objectives:}

- To highlight the risk of cephalic tetarus resulting from penetrating orbital injury.

- To alert ophthalmologists to the importance of ensuring adequate anti-tetanus prophylaxis in all cases of ophthalmic and in particular orbital trauma most especially where foreign body retention is involved or is likely.

Methodology: A case of cephalic tetanus in a 24-year old Nigerian motor mechanic; presenting with torticollis, trismus, facial and neck muscle spasms and multiple cranial nerve palsies affecting the III ${ }^{\text {rd }}, I V^{\text {thi }}, V^{\text {th }}$ and VII $^{\text {th }}$ cranial nerves is reported. This followed a penetrating injury to the left orbit with a retained metallic foreign body. The patient's anti-tetanus immunization status was not known prior to the injury. The patient developed symptoms of cephalic tetanus some days after receiving the anti-tetanus serum intramuscularly. He was treated vigorously with antitetanus serum, intravenous diazepam and fluids, intravenous metronidazole and other parenteral broadspectrum antibiotics. He was also actively immunized with tetanus toxoid injections.

Results: He made a slow but remarkable recovery after about five weeks ( 38 days) with minimal neurological deficit.

Key words: cephalic tetanus, orbital injury, cranial nerves, anti-tetanus prophylaxis, occupational hazard

\section{INTRODUCTION}

Tetanus is an acute infection which affects the nervous system. It is caused by the araerobe, Clostridium tetani and is characterized by increased muscular tone and painful spasms. ${ }^{1-3}$ it presents clinically as generalized, localized, neonatal or cephalic tetanus, with varying degrees of severity. ${ }^{2,3}$ The diagnosis of tetanus is entirely chinical." Every year, tetanus accounts for about one million deaths world wide; $80 \%$ of which occur in Africa and South-east Asia. Tetanus is therefore a disease of public health significance.

Cephalic tetanus is a rare and severe form of localized tetanus characterized by trismus and dysfunction of one or more cranial nerves, especially the VII ${ }^{\text {th }} \cdot{ }^{2,4.5 .67 .78 .9}$ It accounts for between $1-6 \%$ of all cases of tetanus $s^{3,5}$ and most commonly results from head or neck iniuries ${ }^{2-3}$ or ear infection, ${ }^{2,6,10}$ th thas also been reported, however, following dental ${ }^{11}$ maxillofacial, ${ }^{6,72}{ }^{6 r a l^{8}}$ and orbital injury. ${ }^{13}$ Even relatively minor abrasions of the face have resulted in cephalic tetanus. ${ }^{\circ}$ The incidence of cephalic tetanus was as high as $25 \%$ in a review from Abidjar, ${ }^{12}$ the report, however, covered a 23 -year period, and none of the patients had received anti-tetarus prophylaxis.

The mortality rate in some African countries is 15$30 \%{ }^{5}$ The mortality rate is higher than in other forms of localized tetanus ${ }^{l}$ and it can quickly become secondarily generalized with a poor outcome. ${ }^{2,3}$ Some authors ${ }^{1}$ attribute the high prevalence of tetanus in the developing world to poor coverage of the active immunisation schemes. This claim however, has not been proven. The storage and quality of tetanus toxoid are also major issues of concern. ${ }^{1}$ Tetanus is considered a rare disease in the developed world. ${ }^{1.8,19}$ Consequently, there may be a delay in its diagnosis. ${ }^{14}$ The pivotal role of passive immunisation (anti-tetanus prophylaxis) in its prevention and control cannot be overemphasised ${ }^{1,3,5,9,12}$ though tetanus has been reported in a patient who was fully immunised. ${ }^{15}$

Because of its potentially fatal outcome, the awareness of ophthalmologists and primary eye-care professionals in developing countries must be raised to the possibility of this complication arising from

* Author for correspondence 
ophthalmic injury. The need for routine enquiry as to the patient's anti tetanus immunisation status in all cases of ophthalmic trauma no matter how minor it appears then becomes imperative.

\section{CASE REPORT}

A 24 year-old motor mechanic was admitted on $1^{\text {st }}$ October 2002, to the accident and emergency unit ( $A \& E$ ) of the University College Hospital, ibadan with a threeday history of penctrating injury to the left eye from a fragment of motal, which struck his eye while working on an engine block. 'The immediate symptoms included: sudden onset of pain, bleeding from the cye and severe loss of vision; the loss of vision was associated with the progressive swelling and protrusion of the eycball. He administered chloramphenicol eyc drops a few hours after the incident then went to an optician who prescribed analgesics and referred him to the teaching hospital. 'There was no history of use of traditional eye medication.

On examination, the right cye was essentially normal, though visual acuity in the left eye indicated no light perception and he had a left proptosis of $16 \mathrm{~mm}$ (corneo-canthal distance measured $18 \mathrm{~mm}$ and $34 \mathrm{~mm}$ on the right and left respectively). The left eycball was tense, with oedematous lids and periorbital echymosis. There was marked conjunctival chemosis and subconjunctival haemorhage. The cornea was very haxy with an entry wound adjacent to the limbus at 3 o'clock. There was, therefore, no view beyond the cornea.

$\wedge n$ assessment of the penetrating ocular injury was made for panophthalmitis and the possibility of a relained introocular foreign body. The patient was placed on intravenous Zinacef $750 \mathrm{mg}$; llagyl $500 \mathrm{mg}$ with intramuscular Genticin $80 \mathrm{mg}$ being given every 8 hours. Stat doses of anti-tetanus serum, 1500 i.u. and tetanus toxoid $0.5 \mathrm{cc}$ were also given intramuscularly on the second day of admission ( $3^{\text {rd }}$ October 2002), ie, on the patient's arrival at the Eye Ward from A\&L. Orbital $X$-rays and ultrasonography were requested to determine the possibility of a retained foreign body.

The orbital $X$-ray showed a tiny radio-opaque fragment in the left orbit which was not well localized on ultrasonography. However, the ultrasound scan revealed an associated vitreous haemorrhage. Emergency evisceration of the left eye was carried out on the fourth day of admission (5 $5^{\text {th }}$ October 2002) because of the worsening panophthalmitis. During surgery, the left globe was tense and the conjunctiva bled profusely. The ocular tissues were friable, and there was vitreous hacmorrhage and pus in the anterior chamber. No foreign body was found, however, within the globe. Intraocular contents were not histopathologically examined.

Farlier the same day (ie, fourth day of admission and $7^{\mathrm{th}}$ day post-injury), the patient had developed neck pains and stiffness with inability to open his mouth fully. On examination, he had trismus with a dental gap of only $3 \mathrm{~cm}$. He also had right-sided ptosis and bilateral lagophthalmos. He was unable to move his right eye in all directions; the right pupil was mid-dilated and unreaclive. Attempts to do a funduscopic examination of the right eye initiated right torticollis and involuntary spasms of the neck muscles. The patient was not febrile and there were no signs of meningism or generalized tetanus. A clinical diagnosis of cephalic tetanus was made based on the history of penetrating eye injury, trismus, provoked spasms and multiple cranial nerve palsies (III, IV, VI on the right and VII bilaterally). IJ was jointly managed by physicians and ophthalmologists. He received 10,000 i.u. of antitetanus scrum intramuscularly stat., intravenous diazepam $240 \mathrm{mg} / 24 \mathrm{hrs}$ and intravenous dextrose saline alternating with dextrose water. He was not allowed anything orally. Intravenous Zinace $750 \mathrm{mg}$ and Flagyl $500 \mathrm{mg}$ infusions, continued to be administered 8-hourly. His vital signs were monitored hourly and a spasm chart was kept.

After four days, the intravenous diarepam was increased to $320 \mathrm{mg} / 24 \mathrm{hrs}$, due to persistent muscle spasms. 'The patient was maintained on this dose for another 8 days after which he improved significantly. 'The dose was then reduced to $240 \mathrm{mg} / 24 \mathrm{hrs}$, which was maintained at this level for another 8 days until he became spasm free on the $20^{\text {it }}$ day of treatment. He improved steadily and was able to commence oral intake by the $25^{\text {th }}$ day of treatment. 'The intravenous diazepam was replaced with oral tablets $30 \mathrm{mg}$ every 6 hours. The dental gap increased from $3 \mathrm{~mm}$ to $6 \mathrm{~mm}$ and the patient was able to tolerate fluids without developing laryngeal spasms.

When the patient had remained spasm free for 19 days, he was ambulated and discharged 2 days later. He was asked to continue taking oral diazepam $10 \mathrm{mg}$ tablets $2 /$ daily. On the $18^{\text {th }}$ of December 2002, after about 10 weeks of treatment, he was seen for follow-up at the outpatient clinic, and he had improved remarkably. Lid function for the right eye had returned to normal, with complete resolution of the ptosis, however, the patient still had some residual restriction of elevation and adduction with mild residual facioparesis, but he was fully ambulant with normal vision in the right eye.

\section{DISCUSSION}

Clostridium tetani is a slender gram positive bacillus with terminal endospores giving it a typical drumstick appearance. ${ }^{16-18}$ It is an obligate anacrobe with a worldwide distribution. Its main habitat is top soil ${ }^{16.18}$ but it has also been recovered from human ${ }^{16}$ and animal faeces. ${ }^{16,18}$ Spores of $C$. tetoni are highly resistant to heat and antiseptics and can remain dormant in tissues for 
months until conditions suitable for germination arise. ${ }^{18}$ The presence of necrotic tissue, calcium salts and associated pyogenic infection in tissues enhances the pathogenicity of $C$. tetani. ${ }^{16,18}$ The optimum temperature for growth of the bacillus is $37^{\circ} \mathrm{C}^{16}$

The diagnosis of cephalic tetanus is based entirely on clinical features ${ }^{1,16}$ and, therefore, requires a high index of suspicion. ${ }^{8}$ As occurred in this case, the outcome is greatly influenced by early recognition and prompt institution of appropriate therapy. ${ }^{B}$

The patient's history is very important. The time and nature of the predisposing injury must be elicited, as well as any information suggesting wound contamination or a foreign body, as was the case in this patient. The risk of tetanus is increased with soil or animal dung contamination." $16-18$ The interval between injury and the first symptom (incubation period) and between the fixst symptom and first spasm (period of onset) are of prognostic significance. ${ }^{1-3}$ The prognosis is worse when either period is short. ${ }^{2}{ }^{3}$ The usual incubation period ranges from 7-14 days, but may be as short as one day or as long as several months. ${ }^{1.3}$ It is indicative of the distance the toxin must travel within the nervous system. The incubation period in this patient was 7 days, which correlates with the reported average. "The period of onset is usually measured in hours but it has been reported to be as long as many days in a series in India. ${ }^{16} \mathrm{Ir}$ this patient, the period of onset was 9 hours.

Trismus is a common presenting symptom ${ }^{2,16}$ but it is not consistently present in cephalic tetanus. ${ }^{3}$ In $42 \%$ of cases in which trismus was present, it was discovered to have developed after other cranial nerve deficits had occurred. In this case, the patient's initial complaints included trismus, but upon examination there was also concomitant paralysis of cranial nerves III, IV, VI \& VII. The frequency of cranial nerve affectation is in the order: VII, VI, III, IV \& XII.

Multiple ocular cranial nerve palsy in this patient was unlikely to have resulted from cavernous sinus thrombosis because the patient was afebrile, remained clearly conscious and did not have a headache. There were no clinical signs of orbital venous congestion in the contralateral eye. In addition the patient had the characteristic clinical features and painful spasms of tetanus.

The patient's management was stratified as follows:

- General measures, ${ }^{2,3}$ were aimed at removing the source of contamination (via evisceration and monitoring) and maintaining an adequate airway, circulation and normal vital signs.

- Antibiotic therapy was aimed at eliminating the vegetative forms of the bacterium and halting their toxin release. Previously, crystalline penicillin was the mainstay of therapy, at a dose of between 10-12 mega units per day, given for about ten days. ${ }^{1}$ Nonrandomized studies have shown, however, that metronidazole $500 \mathrm{mg} 6$ hourly (or $1 \mathrm{G} 12$ hourly) is equally effective., 2,3 This patient was given intravenous metronidazole.

- Antitoxin therapy was administered to neutralize the exotoxins that were circulating freely. Human immune globulin (HIG) is the ideal treatment at a dose of between 3000-6000 units, given intramuscularly. ${ }^{i-3}$, However, equine antitetanus serum equally provides adequate protection. ${ }^{2}$ its drawbacks are the shorter half-life and the higher risk of severe hypersensitivity reactions. ${ }^{2}$ This patient received $10,000 \mathrm{i}$.u of intramuscular antitetanus serum, without adverse effect.

- Control of muscular spasms was achieved with a benzodiazepine. ${ }^{1,3}$ Although diazeparn was used in this patient, lorazepam and midazolam are effective alternatives. ${ }^{1 \cdot 3}$ The ideal muscle relaxant produces just enough sedation to abort spasms without significant respiratory suppression. ${ }^{2}$ Second line drugs included barbiturates and phenothiazines, like phenobarbitone and chlorpromazine, respectively. Both are employed in the management of neonatal tetanus. ${ }^{1,2,10}$ Patients may need to be anaesthesized to abort severe or excessive spasms and anaesthetic agents like propofol ${ }^{2-3}$ may be employed. The patient may even require respiratory support with a ventilator and endotracheal intubation or trachaeostomy ${ }^{1-3}$ in the event of laryngeal spasm.

- Additional measures employed in the management of tetanus include all the measures taken to decrease undue stimulation of the patient and to prevent the provocation of muscle spasms. ${ }^{2}$

Active immunization with tetanus toxoid and regular booster injections is the recommended means of prevention. ${ }^{1-14}$ In most developed countries, children are fully immunized by the time they reach school age, therefore, the risk is greatest in the elderly and immunocompromised. ${ }^{14}$ In the developing world, the immunization status of most people can hardly be ascertaine ${ }^{18}$ as was the case with this patient. $I t$ is better to give a protective booster as well as passively immunize every patient with trauma irrespective of the degree of injury. ${ }^{728,29}$ An attack of tetarus does not confer immunity on the survivor, therefore, it is imperative to actively imrrunize the patient fully upon recovery. ${ }^{1-3}$

\section{CONCLUSION}

A case of cephalic tetanus resulting from orbito-ocular injury was reported. A high index of suspicion and prompt treatment, jointy by physicians and 
ophthalmologists, achieved success in this case. Imumediate anti-tetanus prophylaxis in all patients with orbito-ocular injuries is known to prevent this lifethreatening condition. Cephalic tetanus may be considered a rare occupational hazard in the Nigerian motor mechanic.

\section{Acknowledgements}

The cooperation and participation of the medical team on call (Gastroenterology Unit) in the management and follow-up of this patient is appreciated.

\section{References}

1. Farrar JJ, Yen LM, Cook T, Fairweather N, Binh N, Parry J et al. Tetanus. J Neurol Neurosurg Psychiatry 2000; 69: 292-301.

2. Abrutyn E. Tetanus. In: Harrison's Principles of Internal Medicine Vol. 1, $14^{\text {th }}$ ed. Fauci AS, Braunwald E, Isselbacher KJ, Wilson JD et al. (eds.) Singapore, McGraw-Hill, 1998; pp 901-904.

3. Bhatia R, Prabhakar S, Grover VK. Tetanus. Neurol Ind 2002; 50(4): 398-407.

4. Kara CO, Cetin CB, Yalcin N. Cephalic tetanus as a result of rooster pecking: An unusual case. Scand f Infect Dis 2002; 34(1): 64-6.

5. Jagoda A, Riggio S, Burguieres T. Cephalic tetanus: A case report and review of literature. Am / Emerg Med 1988; 6(2): 128-30.

6. Gentile M, Lauria G. Cephalic tetanus presenting with incomplete Bell's palsy. Ital J Neurol Sci. 1994; 15(2): $111-3$; comment in: Ital J Neurol Sci. 1995; 16(4): 263.

7. Nakazawa K, Kanda F, Ishihara H, Matsushita T, Chihara K. A case of cephalic tetanus presenting with opisthotonos. Rinsho Shinkeigaku 2001; 41(4-5): 187-90.

8. Dyce O, Bruno JR, Hong D, Silverstein K, Brown MJ, Mirza N. Tongue piercing. The new "rusty nail"? Head Neck 2000; 22(7): 728-32.
9. Scott GI. Movement of the lids in the motor system. In: System of Ophthalmology Vol. 12 (Neuroophthalmology), Duke-ElderS (ed.) London, Henry Kimpton, 1971; p. 938.

10. Fatunde OJ and Familusi JB. Atypical presentations in children with post-neonatal tetanus in Ibadan, Nigeria. Ann Trop Paediatric 2001; 21(1): 72-6.

11. Burgess JA, Wambaugh GW, Koczarski MJ. Report of case: Reviewing cephalic tetanus. I Am Dent Assoc 1992; 123(7): 67-70.

12. Kakou AR, Eholie S, Ehui E, Ble O, Bissagnene E et al. Localised tetanus in Abidjan: Chinical and prognostic features (1976 - 1997). Bull Soc Pathol Exot 2001; 94(4): 308-11.

13. Scott GI. Ocular dissociations in the motor system In: System of Ophthalmology Vol, 12 (Neuroophthalmology), Duke-Elder S. (ed.), London, Henry Kimpton, 1971; p. 761.

14. Bleck TP. Tetanus: Pathophysiology, management and prophylaxis. Dis Mon 1991; 37(9): 545-603.

15. Vieire BI, Dunne JW, Summers Q. Cephalic tetanus in an immunised patient. Clinical and electromyographic findings. Med / Aust 1986;145(34): $156-7$.

16. Enyinnaya Nnochiri. Medical Microbiology in the Tropics. London, Oxford University Press, 1975; $\mathrm{pp}$. 111-112, 189-191.

17. McKendrick GDW. Tetanus. In: Prices Textbook of Medicine, $12^{\text {th }}$ ed. Scott RB (ed.) London: Oxford University Press, 1978; 82-84.

18. Willis A Trevor. Clostridium: The spore-beaning anaerobes. In Topley $\&$ Wilson's Principles of Bacteriology, Virology and Immunity, Vol. $2,8^{\text {th }}$ ed. Parker M Tom, Duerden I Brian, eds. Edward Arnold, London, 1990; pp. 212-227.

19. Vakilb J, Singhal BS, Pandya SS, Irani IF. Cephalic tetanus Neurology 1973; 23: $1091-1096$. 